\title{
Transdisciplinarity in Japan: insights from the Research Institute for Humanity and Nature (RIHN), Kyoto
}

\author{
Cyrille Rigolot ${ }^{*}$ \\ INRAE, UMR Territoires, Saint-Genès-Champanelle, France
}

\begin{abstract}
To date, most debates about transdisciplinarity (TD) have been dominated by Western institutions. This paper proposes insights from the Research Institute for Humanity and Nature (RIHN), Kyoto, Japan, from an investigation as a visiting scientist. After describing its unique project-based organization, I first show that the development of TD at RIHN faces some common challenges, such as TD evaluation, education and upscaling (beyond local contexts). Yet, collaborations with stakeholders have also unique specificities (importance of the group, rigidity of institutions, different ways of interacting...). Moreover, most RIHN researchers claim to have a particularly practical approach to TD. At the level of the whole institute, RIHN gives a strong emphasis on the premise that environmental problems are rooted in human cultures and values. RIHN also develops a specific approach to scales, in which Asia serves as a nodal point between the local and global ('Asia vision'). We suggest that RIHN's emphasis on cultural roots and its nodal approach to scale might be themselves rooted in the Japanese culture.
\end{abstract}

Keywords: research / sustainability / Human-Nature relationship / culture / Asia

Résumé - La transdisciplinarité au Japon : un éclairage depuis le Research Institute for Humanity and Nature (RIHN), Kyoto. Bien que la transdisciplinarité (TD) mette en avant l'importance des savoirs locaux et non occidentaux, les débats internationaux sur la transdisciplinarité elle-même ont été principalement portés par des institutions occidentales. Cet article propose un éclairage depuis le Research Institute for Humanity and Nature (RIHN) à Kyoto, à partir d'une enquête en immersion en tant que chercheur invité. Le RIHN a une structure, unique en son genre, organisée sur projets, décrite dans la première partie de l'article. Le développement de la TD au RIHN est confrontée à des défis classiques, comme ailleurs, tels que les problèmes de l'évaluation de la recherche, la formation et le changement d'échelle (au-delà des contextes locaux). Cependant, les collaborations avec les acteurs au Japon ont aussi des spécificités fortes liées à des facteurs sociologiques (importance du groupe, rigidité des institutions, modes d'interactions différents...). De plus, les chercheurs du RIHN revendiquent une approche essentiellement pratique de la TD. À l'échelle de l'institut dans son ensemble, le RIHN s'appuie fortement sur le postulat selon lequel les problèmes environnementaux sont fondamentalement enracinés dans les cultures et les valeurs humaines. Par ailleurs, le RIHN développe une approche singulière des articulations entre échelles, dans laquelle l'Asie est considérée comme un point nodal entre le local et le global, avec des problématiques particulières de durabilité (importance de la résilience face aux catastrophes, urbanisation rapide...). Nous suggérons que l'insistance du RIHN sur la notion d'enracinement culturel et son approche nodale des articulations entre échelles sont elles-mêmes enracinées dans la culture japonaise et ses relations spécifiques à la nature.

Mots-clés : recherche / durabilité / relations homme-nature / culture / Asie

*Corresponding author: cyrille.rigolot@inrae.fr 


\section{Introduction}

Among many other dimensions, the on-going COVID-19 crisis can be seen as an epistemological cataclysm. Many citizens are now realizing the profound implications that the considerable controversies between professional scientists themselves can have on their everyday lives (lockdown or not...). For sure, the same kind of controversies also exist in the broad field of sustainability sciences, but time scales and complexities might have usually prevented much citizens to be so clearly exposed to them with such a degree of direct involvement as for COVID-19. In this context, transdisciplinarity (TD) more than ever appears as a promising way of producing knowledge and support decision-making (Mallee, 2020). According to a current definition, TD consists in integrating several disciplines (interdisciplinarity) as well as non-academic sources and actors in the process of knowledge production (Lang et al., 2012). Since its emergence in the 70's, TD has evolved along several streams (generally differentiated by the emphasis given to theory and/or to practice [McGregor, 2015]). In recent decades, TD has significantly progressed into a robust and mature discipline of 'integration and implementation' (within the scope of research projects), and/or more broadly as a ubiquitous 'way of being' (Rigolot, 2020).

An increasing number of authors and stakeholders consider that TD should be practiced and taught far more broadly (OECD, 2020). However, to date, the institutionalization of TD has been strongly limited, partly because of path dependencies related to the dominant disciplinary knowledge production regime (Hubert et al., 2013; Hermesse and Vankeerberghen, 2020). Additionally, internal contradictions might have prevented an extensive upscaling of TD. Particularly, although the TD research community stresses the importance of local, indigenous or non-Western knowledge, the debates about TD itself have remained largely dominated by Western scholars (McGregor, 2015; Chilisa, 2017). From a transdisciplinary perspective, every innovation process is influenced by its context of application and the perspectives of local stakeholders. This should be true for TD itself, as an innovation in the field of knowledge production (Cole, 2017). Therefore, a better understanding of the variants of TD in different cultural contexts seems to be essential for its own credibility.

This paper offers a discussion on TD and its institutionalization in Japan, taking as a case study the Research Institute for Humanity and Nature (RIHN, Kyoto). In the last century, Japan has become a highly modernized country, with an academic knowledge production system largely inspired by the West, dominated by universities fundamentally organized in disciplines (Houdart, 2001). However, the Japanese culture remains characterized by specific relationships between humans in society (Curhan et al., 2014) and with nature (Chakroun and Droz, 2020). In this context, RIHN was created twenty years ago (2001) and progressively increased its focus toward the co-design of solutions to real-world problems with stakeholders (i.e. TD). As a visiting scientist at RIHN during three months in 2020, I have investigated TD research practices, by combining interviews and participatory observation. Interviewed people were RIHN managers and project leaders with a broad vision of the institute, as well as individual researchers from multiple disciplines. I have also directly contributed to a research project and participated to key collective meetings, such as the RIHN three days General Meeting and several strategic seminars. Other sources of information were field trips, access to archives and many informal discussions. In the next sections, I first present the organizational structure of the RIHN institute, which is somehow unique in Japan and the world. Then, I show that the development of TD at RIHN faces some challenges commonly described in the international literature, but also possesses some specificities which can be related to the Japanese socio-cultural context.

\section{The Research Institute for Humanity and Nature (RIHN): a unique organizational structure}

In its official presentation document, the stated goal of RIHN is to 'seek concepts, theories and mechanisms capable of describing and enabling transformation of human-environment interactions' (RIHN, 2021). From the beginning (2001), RIHN has promoted interdisciplinary research involving cultural aspects, considering that global environmental problems are caused by cultures or civilizations, but also that cultures can solve the problems (Niles and Abe, 2015). Gradually, RIHN extended its research fields from interdisciplinary to more transdisciplinary, with the explicit goal to 'redefine the role of science in society, improve dialogue between different traditions of knowledge, and stimulate new multi-actor collaborations', drawing on 'multiple perspectives from a range of disciplines including the natural and social sciences, arts and humanities, and engineering and design' (RIHN, 2021). RIHN conducts research at the local, national, international or global scales, but its core focus area is Asia. The key principles of RIHN research are illustrated in Figure 1, which is directly taken from the official presentation document (RIHN, 2021).

The organizational structure of RIHN is based on the succession of research projects (5 or 7 years projects). Each year, ideas for new projects are identified through 


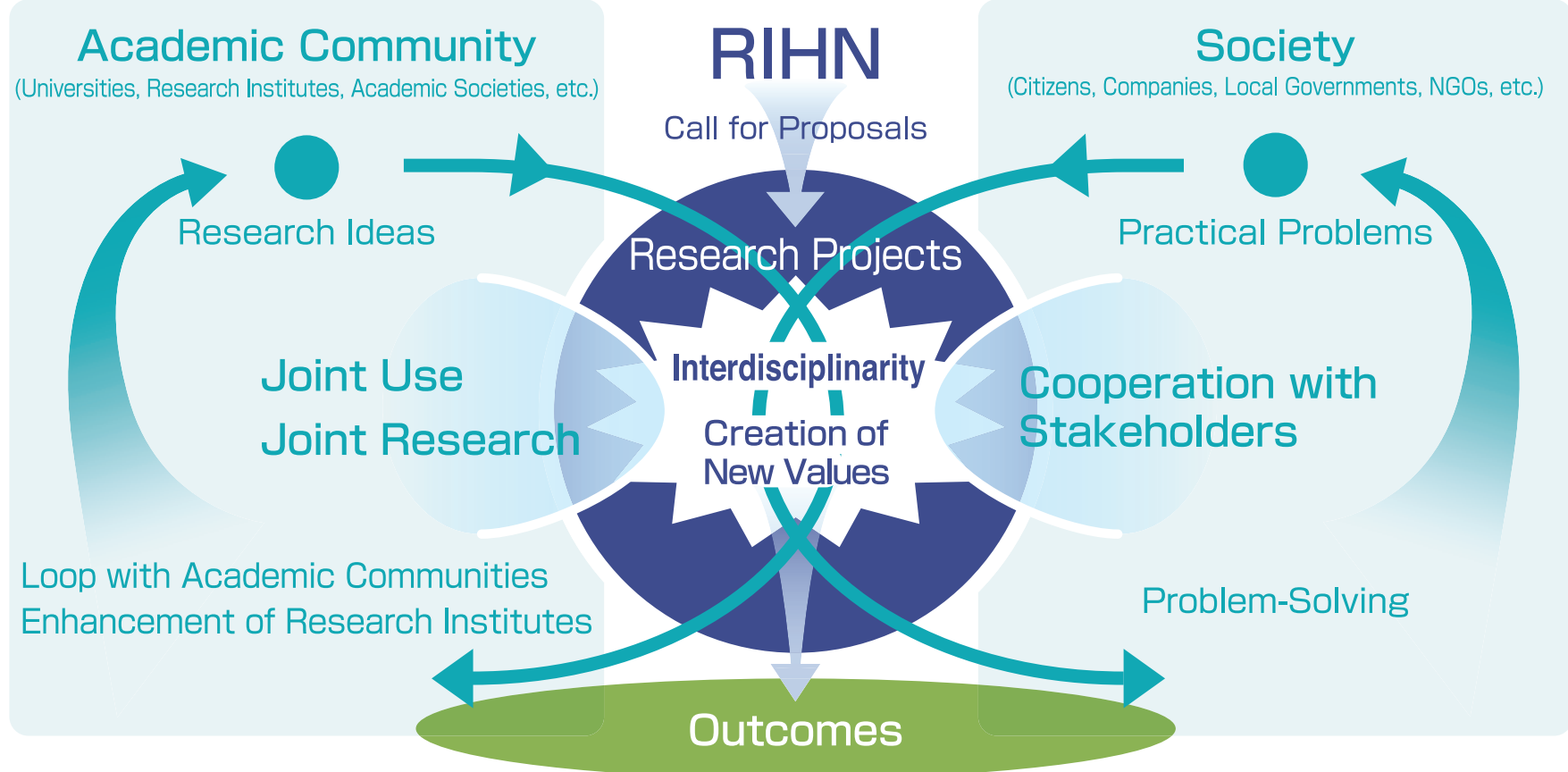

Fig. 1. Key principles of RIHN research. () Research Institute for Humanity and Nature, 2021.

public solicitation. The selected projects then go through successive stages of 'incubation' and 'feasibility', before they become full research projects if they are positively evaluated by an international committee $^{1}$. Since 2016 , research projects have been organized in three structuring programs:

1. Societal transformation under environmental change, with two lines of inquiry: 1.1. Long-term paths of social and economic development in relation to climate change and environmental history; and 1.2. Motivations that affect people's livelihood (Sugihara, 2019);

2. Fair use and management of diverse resources (i.e. exploring resource use across multiple spatial scales and with diverse stakeholders; Kanemoto et al., 2020);

3. Designing lifeworlds of sustainability and wellbeing (by definition, our 'lifeworlds' are composed of the physical spaces and socio-cultural spheres of our everyday lives [McGreevy, 2017]; an example of original RIHN method to design lifeworlds is 'Future Design', as developed by Saijo [2020]).

Additionally, a 'Core program' aims at capitalizing transdisciplinary concepts and methodologies, while developing the reflexivity of the institute. For example, on the basis of RIHN transdisciplinary research projects,

\footnotetext{
${ }^{1}$ A description of a RIHN research project can be found in the website of the just-completed FEAST project on agroecological transitions in Japan and other countries (research program 3): https://www.feastproject.org.
}

Kondo et al. (2019) from the Core program have proposed an 'Open Team Science Methodology' to interlink open science and community-based participatory research for socio-environmental issues. This methodology is based on four key principles (Kondo et al., 2019): 1) Transcend (i.e. identifying common goals beyond actors' conflicting interests); 2) Ethical equity (i.e. inclusiveness, empowerment of marginal actors or 'small voices'); 3) Visualization (related to the transparency of the research process); 4) Dialogue (related to trust between actors). A list of practical checkpoints has been proposed to ensure that these four principles are respected in participatory projects (Kondo et al., 2021). Another illustration of the Core program research is the development of innovative methodologies from and for the RIHN research projects to study the 'Water-EnergyFood' nexus at multiple spatial scales (Taniguchi et al., 2019; Lee et al., 2021).

To support the project-based organization, another originality of RIHN is to house an analytical laboratory, specialized in the study of stable-isotopes (which can be solicited by RIHN researchers or by other institutes or universities). For example, isotopes can be used for topics as diverse as the source and quality of urban groundwater (Hosono et al., 2010), or the geographical origin and purity of food products (Rupprecht et al., 2020a). Since 2015, RIHN also hosts and develops close relationships with the Future Earth Asia Center ${ }^{2}$ (Onishi, 2015). In relation to the global Future Earth Network, the

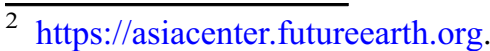


Asia Center aims to facilitate co-design and co-production of research and science-policy engagement for sustainable transformation in Asia and the Pacific, through research enabling, capacity building, networking and communication. Administratively, the analytical lab and Future Earth Asia Center belong to the 'RIHN center', together with three other divisions on communication, information resources and collaborations. The Public Relations Unit and the International Publication Unit complete the institute organizational structure (RIHN, 2021).

Finally, RIHN has developed two programs to invite overseas researchers to contribute directly to the RIHN research community, as a significant part of its strategy. The present investigation on TD research practices at RIHN has been conducted in this context. In the next section, I first show that RIHN shares common challenges with the global TD research community, but that it also has specificities at the level of individual research projects and at the strategic level of the whole institute. My interpretation is based to a large extent on the preexisting huge reflexive work of the institute (as part of the core program and beyond). Moreover, my investigation approach and the following ideas have been discussed with RIHN scholars during two open seminars at the beginning and the end of my visiting period.

\section{RIHN approaches to transdisciplinarity: common challenges and specificities}

\section{Common challenges for the development of inter- and transdisciplinarity at RIHN}

According to the multi-national analysis proposed by Boone et al. (2020) (with a contribution from RIHN), the development of inter- and transdisciplinarity organizations can follow two contrasting pathways: one is to establish a new organization 'de novo', and the other is to merge existing organizations. RIHN is a typical example of 'de novo' organization, created outside the walls of universities (with some resistances and difficulties). Through three successive 'stages' during RIHN's twenty years of existence (corresponding to three different RIHN general directors), the research approaches evolved from mainly interdisciplinary to increasingly transdisciplinary with stakeholders. This evolution corresponds to a transition from a science 'for' society, to a science 'with' society, the later being associated with the notion of 'co-design' which has become central in RIHN strategy. The disciplines involved in RIHN projects also evolved, from mostly natural sciences initially to an increasing inclusion of humanities and social sciences. These evolutions from inter- to transdisciplinarity and toward the inclusion of more human sciences) seem to be relatively common among TD institutes worldwide (Boone et al., 2020).
As a specific institute separated from universities, RIHN has to demonstrate its added value in the Japanese academy, and for the international community. This raises the crucial and very common question of the evaluation of inter- and transdisciplinary sciences. To better communicate about its specificities, for example, RIHN is currently collaborating with statisticians to develop a specific indicator to quantify the diversity of publications quotations (particularly outside their direct research field). The satisfaction of stakeholders and researchers toward different RIHN research projects is also investigated as part of the Core program. Another common issue for TD at RIHN is to generate impacts for sustainability at large scales. Indeed, RIHN research projects are typically performed at the local level ('community-based'). This raises the question of the ability of RIHN research to contribute significantly to solve global environmental changes, and to fulfill the institute's general mission. A related issue is to create lasting sustainable changes, beyond the limited time of research projects. A first response to these challenges is the development of large and highly dynamic networks. The hosting of the Future Earth Asia Center by RIHN plays an important part in this networking, with a significant involvement of RIHN members in the Future Earth's KAN (Knowledge Action Networks). A second strategy to generate impacts beyond local levels is to engage with decision-makers at larger scales. As an example, RIHN has significantly contributed to the development of a 'Japan Strategic Research Agenda (JRSA)' (national scale), with 107 priorities identified through consultations and a workshop with the public, local governments, and the industries. Another common challenge faced by RIHN is the lack of training of TD researchers (as no education program dedicated to TD currently exists in Japanese universities). To foster TD education, RIHN has created a dedicated one-week intensive program ('TERRA school') for early carrier scholars in Asia.

\section{Specificities of transdisciplinary research at RIHN}

\section{Specificities at the level of individual research projects}

RIHN researchers have a diversity of transdisciplinary research practices, and a diversity of definitions of TD. However, beyond diversity, most RIHN researchers claim to have a rather practical approach to TD. According to the leader of a core program project, a wide gap exists between an 'ideal' transdisciplinary process as described in literature (as in Lang et al., 2012), and the 'real' transdisciplinary processes as developed by RIHN researchers. Several interviewees consider that RIHN transdisciplinary research practices are particularly 
practical (even more than the so-called 'practical' TD approach, generally corresponding to the 'Zürich school' [McGregor, 2015]). For these researchers, TD progresses through 'trial and errors', rather than on the basis of some well-defined methodology. In this sense, some researchers who have already a long experience of working with stakeholders can even oppose some resistance to TD, in which they see 'nothing really new'. On the other hand, other researchers consider TD as a radically different way of doing research, and warn against the pitfall of 'putting TD in a small box of mere stakeholders' participation'.

As regards the collaborations with stakeholders themselves, RIHN researchers report some specificities in the Japanese context, such as a lack of political awareness among citizens, the strength of hierarchical relationships and the rigidity of Japanese institutions. These sociological characteristics have consequences on participatory processes (Masuhara et al., 2016), and on the possible ways to cope with some classical TD challenges, such as the management of power asymmetries (Kondo et al., 2019). According to the leader of a core project on serious games, Japanese stakeholders might have difficulties to change their roles, even for 'playing'. Anecdotally, one program leader notes that TD 'works better' just after disasters, when the rigidity of institutions has decreased. In such a sociological context, a description of a successful participatory creation of 'food policy councils' in Kyoto is described by Mangnus et al. (2019), which is part of the RIHN FEAST research project. As regards the dynamics of the collaborations, a specific way of interacting exists in Japan, called 'synlogue', which fosters creative co-design between people. The difference between synlogue and dialogue is illustrated in Figure 2 (adapted from Chen [2020], in Japanese). The practical aspects of synlogue in the context of research projects is currently explored as part of the Open Team science methodology (Kondo et al., 2019, 2021) and by the RIHN Public Relations Unit (RIHN, 2021).

Finally, the Asian context raises specific sustainability challenges: rapid urbanization patterns (mega cities), or resilience to disasters (Taniguchi, 2018). These specificities have implications for the topics of each individual research projects, but also for the strategy of the whole institute, which is developed in the next section.

\section{Specificities at the strategic level of the whole institute}

Although RIHN general strategy has significantly evolved through time, one overarching principle has remained central from the creation of the institute: the explicit premise that "environmental problems are rooted
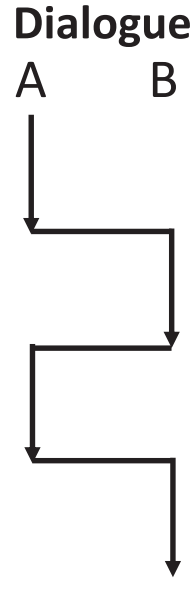

After A finishes talking $B$ begins his story

Differences are emphasized

Subjectivities do not intersect
Synlogue

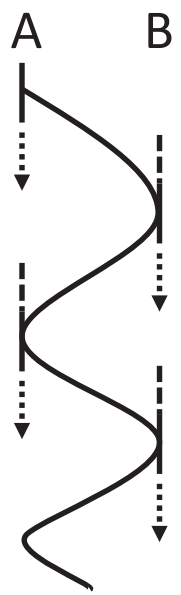

Before A finishes the story $B$ begins to talk

A and $B$ collaborate to make sentences

Subjectivities intersect
Fig. 2. Dialogue and synlogue, as developed by the Open Team science methodology (Kondo et al., 2019, 2021) and RIHN Public Relations Unit (translated from Chen, 2020 ${ }^{4}$ ).

in human society, culture, and values' (RIHN, 2021). This premise implies that RIHN research involves a value dimension, driven by questions such as what the relationship between humanity and nature 'ought to be like'. Although this statement clearly appears as a starting point in the presentation of the institute (RIHN, 2021), a three months investigation as a visiting scientist has been necessary for me to realize how significant it was for most RIHN projects. For example, the leader of the FEAST project has found great support in this value dimension to explore particularly ambitious transformation scenarios for food systems (a nice illustration can be found in the concept of 'multispecies sustainability' [Rupprecht et al., 2020b]). The isotope laboratory is particularly relevant to include some 'cultural-embeddedness' in inter- and transdisciplinary research practices. For example, isotopes in human bones and teeth have been used to understand the food diet of ancient Jomon civilization (Niles and Abe, 2015). Currently, isotopes are used for environmental traceability in watersheds and food labels (Rupprecht et al., 2020a), associated with a user-friendly website for stakeholders ${ }^{3}$. Thanks to the isotope lab, as one researcher says, RIHN is 'able to build on cultural history', which 'makes science meaningful'.

\footnotetext{
3 https://www.environmentalisotope.jp.

${ }^{4}$ Dominique Chen (2020) himself builds on previous work of Nobuko Mizutani. Thanks to Abe K. and Kondo Y. from RIHN for their explanations (the translation is my own).
} 
Another kind of connection to culture is developed by RIHN's Public Relations Unit, through environmental education and collaboration with the arts (ideas of synlogue and a 'RIHN cycle of creativity'). On a theoretical level, taking culture and values as an entry point corresponds to a deep approach to TD, fundamentally related to the notion of 'the experience of Nature' (Niles and Tachimoto, 2018).

Through the years, RIHN has also developed a specific conception of the articulations between different scales, taking Asia as the nodal point between the local and the global. This approach is referred to as the 'Asia vision' (Yasunari et al., 2018). The Asia vision recognizes the huge global significance of the Asian continent: as a whole, monsoon Asia concentrates $60 \%$ of the global population and about one third of global GDP (Yasunari et al., 2018). At the same time, the Asia vision also highlights the great diversity of contexts within and between countries from both the global North (developed) and global South (developing) (Yasunari et al., 2018). As RIHN's mission concerns global environmental changes, the emphasis given to the Asia level is not trivial, and significantly contributes to the identity of the institute. According to some RIHN researchers, compared to other institutes working on global environmental changes (such as International Institute for Applied Systems Analysis, Arizona State University, Stockholm Resilience Center...), the RIHN approach to scale would be specifically grounded and bottom-up, the global scale appearing somehow as 'too far away'.

To some extent, both the emphasis on cultural roots and RIHN's specific approach to scale can be themselves related to the Japanese culture. In Japan, culture is not seen as separated from nature, but rather culture is the way to reveal and to better access nature (typically as in zen gardens, haiku poetry...) (Berque, 2019; Chakroun and Droz, 2020). As developed by the anthropologist of sciences Sophie Houdart (2001), this translates into a conception of universality which is made through 'human forces making the fabric of society', rather than through the forces of a unitary nature, as in Western cultures. This conception of universality is consistent with RIHN's approach of global environmental changes through a 'mosaic of contexts', in which research has to be embedded, rather than through some universal topdown approach.

\section{Conclusion}

Undoubtedly, the Research Institute for Humanity and Nature (RIHN) is a particularly original research organization in Japan and in the world. In the internal debates within the institute, the importance of maintaining RIHN's 'uniqueness', while actively engaging in broader research communities is a major topic, as I have clearly observed during the annual three days general meeting and the two internal seminars where we collectively discussed the present work. These internal debates reveal some controversies, for example about the place that Future Earth should take in RIHN general strategy, or about the extent to which RIHN should structure its activities (or not) around 'mainstream concepts' (such as Sustainable Development Goals [SDG] or nexus approaches) and/or around more specific ideas (like synlogue). In my view, such controversies and the dynamic interplay between 'uniqueness' and 'contribution to the mainstream' are healthy and should be nurtured, as they can foster RIHN's contribution to deep and wide sustainability transformations. This transformative potential could be facilitated if the global TD research community would make more space to cultural and 'place-based' research perspectives, which is precisely an aim of the present article.

Because of its originality, RIHN can certainly be seen as a source of inspiration to develop ambitious transdisciplinary research elsewhere. The emphasis on cultural and value dimensions, as well as the conception of the articulations between scales are probably major characteristics to further investigate. Particularly, it would be interesting to study other Japanese transdisciplinary organizations, notably in the field of sustainability sciences (Komiyama and Takeuchi, 2006). Finally, the RIHN project-based organization also raises important difficulties, such as the precarity of researchers' status, and the long-term conservation of transdisciplinary skills and institutional memories. Obviously, RIHN should not be taken 'as a model' to be applied straightforwardly elsewhere. In the same way, RIHN's specific approach should certainly not be understood as a better way for doing TD (even potentially). In fact, the biggest potential for deep sustainability transformations lies in the cross-fertilization between approaches and cultures. As an illustration, the theoretical framework recently proposed by French geographer and RIHN invited scholar Augustin Berque (2019) nicely shows how a subtle confrontation between Eastern and Western thinking can be extremely useful to overcome the current modern-classical paradigm in which sustainability issues are embedded.

\section{Acknowledgments}

This research was supported by the Visiting Research Fellow scheme of the Research Institute for Humanity and Nature. I want to express my deep gratitude to all RIHN people for their generous contribution to this investigation and my understanding. 


\section{References}

Berque A., 2019. An enquiry into the ontological and logical foundations of sustainability: toward a conceptual integration of the interface 'Nature/Humanity', Global Sustainability, 2, E13, https://doi.org/10.1017/sus.2019.9.

Boone C.G., Pickett S.T., Bammer G., Bawa K., Dunne J.A., Gordon I.J., Hart D., Hellmann J., Miller A., New M., Ometto J.P., Taylor K., Wendorf G., Agrawal A., Bertsch P., Campbell C., Dodd P., Janetos A., Mallee H., 2020. Preparing interdisciplinary leadership for a sustainable future, Sustainability Science, 15, 6, 1723-1733, https://doi. org/10.1007/s11625-020-00823-9.

Chakroun L., Droz L., 2020. Sustainability through landscapes: natural parks, satoyama, and permaculture in Japan, Ecosystems and People, 16, 1, 369-383, https://doi.org/ 10.1080/26395916.2020.1837244.

Chen D., 2020. Mirai-wo Tsukuru Kotoba: Wakariaenasa-wo Tsunagu-tameni (未来をつくる言葉: わ力りあえなさを つなぐために), Tokyo, Shinchosha.

Chilisa B., 2017. Decolonising transdisciplinary research approaches: an African perspective for enhancing knowledge integration in sustainability science, Sustainability Science, 12, 813-827, https://doi.org/10.1007/ s11625-017-0461-1.

Cole A., 2017. Towards an indigenous transdisciplinarity, Transdisciplinary Journal of Engineering \& Science, 8, https://doi.org/10.22545/2017/00091.

Curhan K.B., Levine C.S., Markus H.R., Kitayama S., Park J., Karasawa M., Kawakami N., Love G.D., Coe C.L., Miyamoto Y., Ryff C.D., 2014. Subjective and objective hierarchies and their relations to psychological well-being: a US/Japan comparison, Social Psychological and Personality Science, 5, 8, 855-864, https://doi.org/10.1177/ 1948550614538461.

Hermesse J., Vankeerberghen A., 2020. La recherche transdisciplinaire au sein des institutions d'enseignement supérieur et de recherche, Natures Sciences Sociétés, 28, 3-4, 270-277, https://doi.org/10.1051/nss/2021006.

Hosono T., Siringan F., Yamanaka T., Umezawa Y., Onodera S. I., Nakano T., Taniguchi M., 2010. Application of multiisotope ratios to study the source and quality of urban groundwater in Metro Manila, Philippines, Applied Geochemistry, 25, 6, 900-909, https://doi.org/10.1016/j. apgeochem.2010.03.009.

Houdart S., 2001. Des mouches et des hommes, dans un laboratoire japonais de génétique du comportement, Médecine/Sciences, 17, 12, 1306-1314, https://doi.org/ 10.1051/medsci/200117121306.

Hubert B., Goulet F., Magnani S., Tallon H., Huguenin J., 2013. Agriculture, modèles productifs et options technologiques : orientations et débats, Natures Sciences Sociétés, 21, 1, 71-76, https://doi.org/10.1051/nss/2013085.

Kanemoto K., Shigetomi, Y., Hoang N.T., Okuoka K., Moran D., 2020. Spatial variation in household consumption-based carbon emission inventories for 1200 Japanese cities,
Environmental Research Letters, 15, 11, 114053, https:// doi.org/10.1088/1748-9326/abc045.

Komiyama H., Takeuchi K., 2006. Sustainability science: building a new discipline, Sustainability Science, 1, 1-6, https://doi.org/10.1007/s11625-006-0007-4.

Kondo Y., Miyata A., Ikeuchi U., Nakahara S., Nakashima K.I., Ōnishi H., Osawa T., Ota K., Sato K., Ushijima K., Vienni Baptista B., Kumazawa T., Hayashi K., Murayama Y., Okuda N., Nakanishi H., 2019. Interlinking open science and community-based participatory research for socio-environmental issues, Current Opinion in Environmental Sustainability, 39, 54-61, https://doi.org/10.1016/j.cosust.2019.07.001.

Kondo Y., Fujisawa E., Ishikawa K., Nakahara S., Matsushita K., Asano S., Kamatani K., Suetsugu S., Kano K., Kumazawa T., Sato K., Okuda N., 2021. Community capability building for environmental conservation in Lake Biwa (Japan) through an adaptive and abductive approach, Socio-Ecological Practice Research, 3, 167-183, https:// doi.org/10.1007/s42532-021-00078-3.

Lang D.J., Wiek A., Bergmann M., Stauffacher M., Martens P., Moll P., Swilling M., Thomas C.J., 2012. Transdisciplinary research in sustainability science: practice, principles, and challenges, Sustainability Science, 7, 25-43, https://doi.org/ 10.1007/s11625-011-0149-x.

Lee S.H., Taniguchi M., Masuhara N., Mohtar R.H., Yoo S.H., Haraguchi M., 2021. Analysis of industrial water-energylabor nexus zones for economic and resource-based impact assessment, Resources, Conservation and Recycling, 169, 105483, https://doi.org/10.1016/j.resconrec.2021.105483.

Mallee H., 2020. A time for transdisciplinarity, Current Opinion in Environmental Sustainability, 46, 16-17, https:// doi.org/10.1016/j.cosust.2020.09.011.

Mangnus A.C., Vervoort J.M., McGreevy S., Ota K., Rupprecht C., Oga M., Kobayashi M., 2019. New pathways for governing food system transformations: a pluralistic practice-based futures approach using visioning, backcasting, and serious gaming, Ecology and Society, 24, 4, 2, https://doi.org/10.5751/ES-11014-240402.

Masuhara N., Baba K., Tokai A., 2016. Clarifying relationships between participatory approaches, issues, processes, and results, through crosscutting case analysis in Japan's environmental, energy, and food policy areas, Environment Systems and Decisions, 36, 4, 421-437, https://doi.org/ 10.1007/s10669-016-9613-6.

McGregor S.L.T., 2015. The Nicolescuian and Zurich approaches to transdisciplinarity, Integral Leadership Review, 6, 16, http://integralleadershipreview.com/ 13135-616-the-nicolescuian-and-zurich-approaches-totransdisciplinarity/.

McGreevy S.R., 2017. Lifeworlds as pedagogy for sociocultural change: sensuous food futures, practices, and meaning in everyday experience, in Conference proceedings for the 11th RIHN international symposium: Asia's transformations to sustainability: past, present and future of the Anthropocene, 2017.03.10 - 2017.03.11, Kyoto, Research Institute for Humanity and Nature. 
Niles D., Abe K.I. (Eds), 2015. Humanity and Nature in the Japanese Archipelago, Kyoto, Research Institute for Humanity and Nature.

Niles D., Tachimoto N., 2018. Science and the experience of nature, Nature Sustainability, 1, 540-543, https://doi.org/ 10.1038/s41893-018-0124-y.

OECD (Organisation for Economic Co-operation and Development), 2020. Addressing societal challenges using transdisciplinary research, OECD Science, Technology and Industry Policy Papers, June, 88, https://doi.org/ 10.1787/0ca0ca45-en.

Onishi Y., 2015. Environmental information infrastructure strategies in Future Earth. Communication at Japan Geoscience Union Meeting, May 24-28th, Chiba, Japan.

RIHN (Research Institute for Humanity and Nature), 2021. Prospectus 2021-2022. https://www.chikyu.ac.jp/rihn_e/.

Rigolot C., 2020. Transdisciplinarity as a discipline and a way of being: complementarities and creative tensions, Humanities and Social Sciences Communications, 7, 100, https:// doi.org/10.1057/s41599-020-00598-5.

Rupprecht C.D., Fujiyoshi L., McGreevy S.R., Tayasu I., 2020a. Trust me? Consumer trust in expert information on food product labels, Food and Chemical Toxicology, 137, 111170, https://doi.org/10.1016/j.fct.2020.111170.

Rupprecht C.D., Vervoort J., Berthelsen C., Mangnus A., Osborne N., Thompson K., Urushima A.Y.F., Kóvskaya M., Spiegelberg M., Cristiano S., Springett J., Marschütz B.,
Flies E.J., McGreevy S.R., Droz L., Breed M.F., Gan J., Shinkai R., Kawai A., 2020b. Multispecies sustainability, Global Sustainability, 3, E34, https://doi.org/10.1017/ sus.2020.28.

Saijo T., 2020. Future design: bequeathing sustainable natural environments and sustainable societies to future generations, Sustainability, 12, 16, 6467, https://doi.org/10.3390/ su12166467.

Sugihara K., 2019. Multiple paths to industrialization: a global context of the rise of emerging states, in Otsuka K., Sugihara K. (Eds), Paths to the emerging state in Asia and Africa, Singapore, Springer, 1-33.

Taniguchi M., 2018. Asian groundwater perspective for global change and Future Earth, in Beer T., Li J., Alverson K. (Eds), Global change and Future Earth. The geoscience perspective, Cambridge, Cambridge University Press, 179186, https://doi.org/10.1017/9781316761489.018.

Taniguchi M., Burnett K.M., Shimada J., Hosono T., Wada C. A., Ide K., 2019. Recovery of lost nexus synergy via payment for environmental services in Kumamoto, Japan, Frontiers in Environmental Science, 7, https://doi.org/ 10.3389/fenvs.2019.00028.

Yasunari T., Mallee H., Ishii R., 2018. Asia's sustainability challenges and Future Earth, in Beer T., Li J., Alverson K. (Eds), Global change and Future Earth. The geoscience perspective, Cambridge, Cambridge University Press, 388397, https://doi.org/10.1017/9781316761489.038.

Cite this article as: Rigolot $\mathrm{C}$. Transdisciplinarity in Japan: insights from the Research Institute for Humanity and Nature (RIHN), Kyoto. Nat. Sci. Soc., 29, 4, 450-457. 